\title{
A Posteriori Error Estimates for a Semidiscrete Parabolic Integrodifferential Control on Multimeshes
}

\author{
Wanfang Shen \\ School of Mathematic and Quantitative Economics, Shandong University of Finance and Economics, \\ Jinan 250014, China \\ Correspondence should be addressed to Wanfang Shen, wanfangshen@gmail.com
}

Received 18 August 2012; Accepted 26 September 2012

Academic Editor: Hua Su

Copyright (C) 2012 Wanfang Shen. This is an open access article distributed under the Creative Commons Attribution License, which permits unrestricted use, distribution, and reproduction in any medium, provided the original work is properly cited.

\begin{abstract}
We extend the existing techniques to study semidiscrete adaptive finite element approximation schemes for a constrained optimal control problem governed by parabolic integrodifferential equations. The control problem involves time accumulation and the control constrain is given in an integral obstacle sense. We first prove the uniqueness and existence of the solution of this optimal control problem. We then derive the upper a posteriori error estimators for both the state and the control approximation, which are useful indicators in adaptive multimesh finite element approximation schemes.
\end{abstract}

\section{Introduction}

For the last twenty years great progress has been made on standard finite element approximation of optimal control problems governed by elliptic or parabolic equations; see, for example, [1-9], although it is impossible to give even a very brief review here. More specifically, research on finite element approximation of parabolic optimal control problems can be found in, for example, $[10,11]$. Systematic introduction of the finite element method for PDEs and optimal control problems can be found in, for example, [5, 12, 13].

In many real modeling applications it is important to consider time accumulation. Parabolic integrodifferential equations and their control of this nature appear in heat conduction in materials with memory, population dynamics, and viscoelasticity; see, for example, Friedman and Shinbrot [14], Heard [15], and Renardy et al. [16]. This calls for more studies on the finite element approximation on integrodifferential equations. For instance, finite element methods for parabolic integrodifferential equations with a smooth kernel have 
been discussed in, for example, Cannon et al. [17], Sloan and Thomée [18], and Yanik and Fairweather [19].

Recently adaptive finite element method has been widely studied and applied in practical control computations. In order to obtain a numerical solution of acceptable accuracy for the optimal control problem, the finite element meshes have to be refined according to a mesh refinement scheme. Adaptive finite element approximation uses a posteriori indicators to guide the mesh refinement procedure. Only the area where the error indicator is larger will be refined so that a higher density of nodes is distributed over the area where the solution is difficult to approximate. In this sense efficiency and reliability of adaptive finite element approximation rely very much on the error indicator used.

Adaptive finite element schemes have been widely studied for some optimal control problems governed by elliptic and parabolic PDEs as well. Some of recent accounts of progress can be found, for example, in [11, 20, 21]. Although there exists so much progress in adaptive finite element elliptic and parabolic control problems, it is much more complicated to study and implement adaptive multimeshes computational schemes for parabolic integrodifferential control problems. More specificity, there has been a lack of a posteriori error estimates for any parabolic integrodifferential control problem, in spite of the fact that such control problems are widely encountered in practical engineering applications and scientific computations as we discussed above.

In this work, we extend the results and the techniques used in [20-22] to a quadratic optimal control problem governed by a linear parabolic integrodifferential equation, which can be generalized to the control problems with more general objective functions. The semidiscrete finite element scheme for this problem is presented. We derive the upper a posteriori error estimates for the semidiscrete finite element approximation for the case where the control constraints are given in an integral sense: $U_{a d}=\left\{v \in X ; \int_{\Omega_{U}} v \geqslant 0, t \in[0, T]\right\}$.

We are interested in the following optimal control problems:

$$
\min _{u \in U_{a d} \subset X} J(u, y(u))=\int_{0}^{T}(g(y)+h(u)) d t
$$

subject to

$$
\begin{gathered}
y_{t}+\alpha y+\int_{0}^{t} \gamma(t, \tau) y(\tau) d \tau=f+B u, \quad \text { in } \Omega \times(0, T], \\
y=0, \quad \text { on } \partial \Omega \times[0, T] \\
\left.y\right|_{t=0}=y^{0}, \quad \text { in } \Omega,
\end{gathered}
$$

where $\Omega$ and $\Omega_{U}$ are bounded open sets in $R^{n}(n \geqslant 2)$ with the Lipschitz boundary $\partial \Omega$ and $\partial \Omega_{U}, y^{0} \in H_{0}^{1}(\Omega), f \in L^{2}\left(0, T ; L^{2}(\Omega)\right), U=L^{2}\left(\Omega_{U}\right), X=L^{2}(0, T ; U), U_{a d} \subseteq X$ is a closed convex subset; $\alpha$ is a linear strongly elliptic self-adjoint partial differential operator of second order with coefficients depending smoothly on spacial variables, $\gamma(t, \tau)$ is an arbitrary second-order linear partial differential operator, with coefficients depending smoothly on both of time and spacial variables in the closure of their respective domains, and $B$ is a suitable linear and continuous operator.

Here we assume $g(\cdot)$ is a convex functional which is continuously differential on $L^{2}(\Omega)$, and $h(\cdot)$ is a strictly convex continuously differential functional on $U$. We further 
assume that $h(u) \rightarrow+\infty$ as $\|u\|_{U} \rightarrow+\infty$ and that $g(\cdot)$ is bounded below. Details will be specified later.

The plan of the paper is as follows: in Section 2, we give the weak formulation and prove the existence and uniqueness of the solution for this optimal control problem. In Section 3, we will give a brief review on the finite element methods and optimality conditions and construct the semidiscrete finite element approximation schemes for the optimal control problem. In Section 4, the upper a posteriori error bounds in $L^{2}\left(0, T ; H^{1}(\Omega)\right)$-norm are derived for the control problem. In Section 5, we obtain the a posteriori error bounds in $L^{2}\left(0, T ; L^{2}(\Omega)\right)$-norm for the control problem.

\section{Existence and Uniqueness of the Solution of the Model Problem}

In this paper, we adopt the standard notation $W^{m, q}(\Omega)$ for Sobolev spaces on $\Omega$ with norm $\|\cdot\|_{m, q, \Omega}$, and seminorm $|\cdot|_{m, q, \Omega}$. We set $W_{0}^{m, q}(\Omega)=\left\{w \in W^{m, q}(\Omega):\left.w\right|_{\partial \Omega}=0\right\}$. We denote $W^{m, 2}(\Omega)\left(W_{0}^{m, 2}(\Omega)\right)$ by $H^{m}(\Omega)\left(H_{0}^{m}(\Omega)\right)$, with norm $\|\cdot\|_{m, \Omega}$, and seminorm $|\cdot|_{m, \Omega}$. In addition $c$ or $C$ denotes a general positive constant independent of $h$.

We denote by $L^{s}\left(0, T ; W^{m, q}(\Omega)\right)$ the Banach space of all $L^{s}$ integrable functions from $(0, T)$ into $W^{m, q}(\Omega)$ with norm $\|v\|_{L^{s}\left(0, T ; W^{m, q}(\Omega)\right)}=\left(\int_{0}^{T}\|v\|_{W^{m, q}(\Omega)}^{s} d t\right)^{1 / s}$ for $s \in[1, \infty)$ and the standard modification for $s=\infty$. Similarly, one can define the spaces $H^{1}\left(0, T ; W^{m, q}(\Omega)\right)$ and $C^{k}\left(0, T ; W^{m, q}(\Omega)\right)$. The details can be found in [23]. To fix idea, we will take the state space $W=L^{2}(0, T ; V)$ with $V=H_{0}^{1}(\Omega)$ and the control space $X=L^{2}(0, T ; U)$. Let the observation space be $Y=L^{2}(0, T ; H)$ with $H=L^{2}(\Omega)$.

Let

$$
\begin{gathered}
\left(f_{1}, f_{2}\right)=\int_{\Omega} f_{1} f_{2}, \quad \forall\left(f_{1}, f_{2}\right) \in H \times H, \\
(u, v)_{U}=\int_{\Omega_{U}} u v, \quad \forall(u, v) \in U \times U, \\
a(z, \omega)=(\alpha z, \omega), \quad c(t, \tau ; z, \omega)=(\gamma(t, \tau) z, \omega), \quad \forall z, w \in V \times V .
\end{gathered}
$$

Assume that there are constants $c$ and $C$, such that for all $t, \tau \in[0, T]$ :

$$
\begin{aligned}
& \text { (a) } a(z, z) \geqslant c\|z\|_{1, \Omega}^{2}, \quad \forall z \in V, \\
& \text { (b) }|a(z, w)| \leqslant C\|z\|_{1, \Omega}\|w\|_{1, \Omega}, \quad \forall z, w \in V, \\
& \text { (c) }|c(t, \tau ; z, w)| \leqslant C\|z\|_{1, \Omega}\|w\|_{1, \Omega}, \quad \forall z, w \in V .
\end{aligned}
$$

We will assume the following convexity conditions:

$$
\left(h^{\prime}(u)-h^{\prime}(v), u-v\right) \geqslant c\|u-v\|_{0, \Omega_{U^{\prime}}}^{2} \quad \forall u, v \in L^{2}\left(\Omega_{U}\right),
$$

that is to say $h(\cdot)$ is uniformly convex. 
Noting that $g(\cdot)$ is convex, it is easy to see that

$$
\left(g^{\prime}(u)-g^{\prime}(v), u-v\right) \geqslant 0, \quad \forall u, v \in H^{1}(\Omega) .
$$

Also, we have that

$$
|B v, w| \leqslant c\|v\|_{0, \Omega_{U}}\|w\|_{0, \Omega}, \quad \forall v \in L^{2}\left(\Omega_{U}\right), u \in H^{1}(\Omega)
$$

because $B$ is a bounded linear operator. (OCP):

Therefore the above-mentioned control problem (1.1)-(1.2) can be restated as follows

$$
\begin{gathered}
\min _{u \in U_{a d}} J(u, y(u))=\int_{0}^{T}(g(y)+h(u)) d t \\
\left(\frac{\partial y}{\partial t}, w\right)+a(y, w)+\int_{0}^{t} c(t, \tau ; y(\tau), w) d \tau=(f+B u, w), \quad \forall w \in V, t \in(0, T] \\
\left.y\right|_{t=0}=y^{0}
\end{gathered}
$$

where $B$ is a linear bounded operator from $L^{2}\left(\Omega_{U}\right)$ to $L^{2}(\Omega)$ and independent with $t$.

From Yanik and Fairweather [19], we know that the above state equation has at least one solution $y \in W(0, T)=\left\{w \in L^{2}\left(0, T ; H^{1}(\Omega)\right), w_{t}^{\prime} \in L^{2}\left(0, T ; H^{-1}(\Omega)\right)\right\}$. For the existence and uniqueness of the solution of the system (2.6), we have the following lemmas.

Lemma 2.1. For the optimal control problem (2.6), there exists the unique solution $(u, y)$, such that $u \in X$ and $y \in L^{\infty}\left(0, T ; L^{2}(\Omega)\right) \cap L^{2}\left(0, T ; H_{0}^{1}(\Omega)\right)$ and $\partial y / \partial t \in L^{2}\left(0, T ; H^{-1}(\Omega)\right)$.

Proof. Assume that $\left\{\left(u^{n}, y^{n}\right)\right\}_{n=1}^{\infty}$ is a minimization sequence for the problem (2.6). It follows that $\left\{u^{n}\right\}_{n=1}^{\infty}$ are bounded in $L^{2}\left(0, T ; L^{2}\left(\Omega_{U}\right)\right)$. Therefore there is a subsequence of $\left\{u^{n}\right\}_{n=1}^{\infty}$ (still denoted by $\left.\left\{u^{n}\right\}_{n=1}^{\infty}\right)$ such that $u^{n}$ converges to $u^{*}$ weakly in $L^{2}\left(0, T ; L^{2}\left(\Omega_{U}\right)\right)$. It is clear that for the subsequence $u^{n}$

$$
\left(\frac{\partial y^{n}}{\partial t}, w\right)+a\left(y^{n}, w\right)+\int_{0}^{t} c\left(t, \tau ; y^{n}(\tau), w(t)\right) d \tau=\left(f+B u^{n}, w\right), \quad \forall w \in V, t \in(0, T]
$$

By taking $w=y^{n}$ and integrating time from 0 to $t$ in (2.7), and applying Gronwall's inequality, we have

$$
\begin{gathered}
\int_{0}^{T}\left\|y^{n}\right\|_{1, \Omega}^{2} d \tau \leqslant C\left(\left\|y^{0}\right\|_{0, \Omega}^{2}+\int_{0}^{T}\left(\|f\|_{-1, \Omega}^{2}+\left\|u^{n}\right\|_{0, \Omega u}^{2}\right)\right) e^{C T} \leqslant C^{*}<\infty, \\
\max _{0 \leqslant t \leqslant T}\left\|y^{n}(t)\right\|_{0, \Omega}^{2} \leqslant C\left\{\left\|y^{0}\right\|_{0, \Omega}^{2}+\int_{0}^{T}\left(\|f\|_{-1, \Omega}^{2}+\left\|u^{n}\right\|_{0, \Omega u}^{2}\right)+\int_{0}^{T} \int_{0}^{t}\left\|y^{n}(\tau)\right\|_{1, \Omega}^{2} d \tau d t\right\} \leqslant C .
\end{gathered}
$$


This infers that $u^{n} \in L^{2}\left(0, T ; L^{2}\left(\Omega_{U}\right)\right)$ and $y^{n} \in L^{\infty}\left(0, T ; L^{2}(\Omega)\right) \cap L^{2}\left(0, T ; H^{1}(\Omega)\right)$, and

$$
\begin{gathered}
u^{n} \longrightarrow u \quad \text { weakly in } L^{2}\left(0, T ; L^{2}\left(\Omega_{U}\right)\right), \\
y^{n} \longrightarrow y \quad \text { weakly in } L^{\infty}\left(0, T ; L^{2}(\Omega)\right) \bigcap L^{2}\left(0, T ; H^{1}(\Omega)\right), \\
y^{n}(T) \longrightarrow y(T) \quad \text { weakly in } L^{2}(\Omega) .
\end{gathered}
$$

Now let us integrate time from 0 to $T$ in (2.7) and take limits as $n \rightarrow \infty$. Clearly we have

$$
\begin{gathered}
(y(T), w(T))-\left(y^{0}, w(0)\right)-\int_{0}^{T}\left(y, w_{t}^{\prime}\right) d t+\int_{0}^{T} a(y, w) d t+\int_{0}^{T} \int_{0}^{t} c(t, \tau ; y(\tau), w(t)) d \tau d t \\
\quad=\int_{0}^{T}(f+B u, w) d t, \quad \forall w \in W(0, T) .
\end{gathered}
$$

Therefore

$$
\begin{gathered}
\int_{0}^{T}\left(\frac{\partial y}{\partial t}, w\right) d t+\int_{0}^{T} a(y, w) d t+\int_{0}^{T} \int_{0}^{t} c(t, \tau ; y(\tau), w(t)) d \tau d t \\
=\int_{0}^{T}(f+B u, w) d t, \quad \forall w \in W(0, T) .
\end{gathered}
$$

Furthermore, we have

$$
\begin{aligned}
\left\|\frac{\partial y}{\partial t}\right\|_{L^{2}\left(0, T ; H^{-1}(\Omega)\right)} & =\sup _{w \in L^{2}\left(0, T ; H_{0}^{1}(\Omega)\right)} \frac{\int_{0}^{T}(\partial y / \partial t, w) d t}{\|w\|_{L^{2}\left(0, T ; H_{0}^{1}(\Omega)\right)}} \\
& \leqslant C\left(\left\|y^{0}\right\|_{0, \Omega}^{2}+\int_{0}^{T}\left(\|f\|_{-1, \Omega}^{2}+\|u\|_{0, \Omega_{U}}^{2}\right) d t\right) e^{C T} .
\end{aligned}
$$

It follows that $\partial y / \partial t \in L^{2}\left(0, T ; H^{-1}(\Omega)\right)$.

Since $g(\cdot)$ is a convex function on space $L^{2}\left(0, T ; L^{2}(\Omega)\right)$ and $h(\cdot)$ is a strictly convex function on $U_{a d}$, we have

$$
\int_{0}^{T}(g(y)+h(u)) d t \leqslant \lim _{n \rightarrow \infty} \int_{0}^{T}\left(g\left(y^{n}\right)+h\left(u^{n}\right)\right) d t .
$$

It follows that $(u, y)$ is one solution of (2.6). Because $J(u, y(u))$ is a strictly convex function on $U_{a d}$, we have that the solution for the minimization problem (2.6) is unique. The proof of Lemma 2.1 is completed. 
Remark 2.2. Here we suppose that the operator $\alpha$ is independent of time variable $t$. The above results can also be applied to the case $\alpha=\alpha(x, t)$ provided that suitable conditions for the operator $\alpha$ are to be imposed.

\section{Finite Element Approximation of Control}

In this section, we firstly state the optimality conditions and set up the finite element approximation for optimal control problems governed by parabolic integrodifferential equation.

It follows from [24] that we can similarly deduce the following optimality conditions of the problem (2.6).

Theorem 3.1. A pair $(y, u) \in\left(L^{2}\left(0, T ; H_{0}^{1}(\Omega)\right) \cap L^{\infty}\left(0, T ; L^{2}(\Omega)\right)\right) \times L^{2}\left(0, T ; L^{2}\left(\Omega_{U}\right)\right)$ is the solution of the optimal control problem (2.6), if and only if there exists a costate $p \in L^{2}\left(0, T ; H_{0}^{1}(\Omega)\right) \cap$ $L^{\infty}\left(0, T ; L^{2}(\Omega)\right)$ such that the triple $(y, p, u)$ satisfies the following optimality conditions:

$$
\begin{gathered}
\left(\frac{\partial y}{\partial t}, w\right)+a(y, w)+\int_{0}^{t} c(t, \tau ; y(\tau), w(t)) d \tau=(f+B u, w), \quad \forall w \in V, t \in(0, T], \\
\left.y\right|_{t=0}=y^{0} \\
-\left(q, \frac{\partial p}{\partial t}\right)+a(q, p)+\int_{t}^{T} c(\tau, t ; q(t), p(\tau)) d \tau=\left(y-z_{d}, q\right), \quad \forall q \in V, t \in[0, T), \\
\left.p\right|_{t=T}=0, \\
\int_{0}^{T}\left(h^{\prime}(u)+B^{*} p, v-u\right)_{U} d t \geqslant 0, \quad \forall v \in U_{a d}
\end{gathered}
$$

where $B^{*}$ is the adjoint operator of $B$.

In the following, we construct the semidiscrete finite element approximation of the control problem (2.6) by approximating the optimality conditions.

Let $\Omega^{h}$ be a polygonal approximation to $\Omega$ with boundary $\partial \Omega^{h}$. For simplicity, we assume that $\Omega$ is a convex polygon so that $\Omega=\Omega^{h}$. Let $T^{h}$ be a partitioning of $\Omega^{h}$ into disjoint regular $n$-simplices $\tau$, so that $\bar{\Omega}^{h}=\bigcup_{\tau \in T^{h}} \bar{\tau}$. Each element has at most one face on $\partial \Omega^{h}$, and $\bar{\tau}$ and $\bar{\tau}^{\prime}$ have either only one common vertex or a whole edge or face if $\bar{\tau}$ and $\bar{\tau}^{\prime} \in T^{h}$. As usual, $h$ denotes the diameter of the triangulation $T^{h}$.

Associated with $T^{h}$ is a finite-dimensional subspace $S^{h}$ of $C\left(\bar{\Omega}^{h}\right)$, such that $\left.\chi\right|_{\tau}$ are polynomials of $m(m \geqslant 1)$ order for all $\chi \in S^{h}$ and $\tau \in T^{h}$. Let $V^{h}=S^{h} \cap H_{0}^{1}(\Omega)$. Note that we do not impose a continuity requirement. It is easy to see that $V^{h} \subset V, W^{h} \subset W$.

Let $T_{U}^{h}$ be a partitioning of $\Omega_{U}^{h}$ into disjoint regular $n$-simplices $\tau_{U}$, so that $\bar{\Omega}_{U}^{h}=$ $\bigcup_{\tau_{U} \in T_{U}^{h}} \bar{\tau}_{U}$. For simplicity, we again assume that $\Omega_{U}$ is a convex polygon so that $\Omega_{U}=\Omega_{U}^{h}$. $\bar{\tau}_{U}$ and $\bar{\tau}_{U}^{\prime}$ have either only one common vertex or a whole edge or face if $\bar{\tau}_{U}$ and $\bar{\tau}_{U}^{\prime} \in T_{U}^{h}$. Let $h_{\tau}\left(h_{\tau_{U}}\right)$ denote the maximum diameter of the element $\tau\left(\tau_{U}\right)$ in $T^{h}\left(T_{U}^{h}\right)$.

Associated with $T_{U}^{h}$ is another finite-dimensional subspace $U^{h}$ of $L^{2}\left(\Omega_{U}^{h}\right)$, such that $\left.\chi\right|_{\tau_{U}}$ are polynomials of order $m(m \geqslant 0)$ for all $\chi \in U^{h}$ and $\tau_{U} \in T_{U}^{h}$. Here there is no 
requirement for the continuity. Let $X^{h}=L^{2}\left(0, T ; U^{h}\right)$. It is easy to see that $X^{h} \subset X$. Let $h_{\tau}\left(h_{\tau_{U}}\right)$ denote the maximum diameter of the element $\tau\left(\tau_{U}\right)$ in $T^{h}\left(T_{U}^{h}\right)$.

In this paper we only consider the piecewise constant finite element space for the approximation of the control for the reason of the limited regularity of the optimal control $u$ in general. For ease of exposition, in this paper we assume that $U_{a d}^{h} \subset U_{a d} \cap X^{h}$.

In order to derive a posteriori error estimates of residual type, we need the following important lemmas.

Lemma 3.2 (see [12]). Let $\widehat{\pi}_{h}$ be the standard Lagrange interpolation operator. For $m=0$ or 1 , $q>n / 2$ and $v \in W^{2, q}(\Omega)$,

$$
\left|v-\widehat{\pi}_{h} v\right|_{m, q, \Omega} \leqslant C h^{2-m}|v|_{2, q, \Omega} .
$$

Lemma 3.3 (see [25]). Let $\pi_{h}$ be the average interpolation operator defined in [25]. For $m=0$ or 1 , $1 \leqslant q \leqslant \infty$ and for all $v \in W^{1, q}\left(\Omega^{h}\right)$

$$
\left|v-\pi_{h} v\right|_{m, q, \tau} \leqslant \sum_{\bar{\tau}^{\prime} \cap \bar{\tau} \neq \emptyset} C h_{\tau}^{1-m}|v|_{1, q, \tau^{\prime}}
$$

Lemma 3.4 (see [26]). For all $v \in W^{1, q}(\Omega), 1 \leqslant q<\infty$

$$
\|v\|_{0, q, \partial \tau} \leqslant C\left(h_{\tau}^{-1 / q}\|v\|_{0, q, \tau}+h_{\tau}^{1-1 / q}|v|_{1, q, \tau}\right) .
$$

Then a possible semidiscrete finite element approximation of (OCP) is thus defined by $(\mathrm{OCP})^{h}$ :

$$
\min _{u_{h} \in U_{a d}^{h}} J\left(u_{h}, y_{h}\right)=\int_{0}^{T}\left(g\left(y_{h}\right)+h\left(u_{h}\right)\right) d t
$$

subject to

$$
\begin{gathered}
\left(\frac{\partial y_{h}}{\partial t}, w_{h}\right)+a\left(y_{h}, w_{h}\right)+\int_{0}^{t} c\left(t, \tau ; y_{h}(\tau), w_{h}(t)\right) d \tau=\left(f+B u_{h}, w_{h}\right), \quad \forall w_{h} \in V^{h}, t \in(0, T] \\
\left.y_{h}\right|_{t=0}=y_{h^{\prime}}^{0}
\end{gathered}
$$

where $y_{h} \in W^{h}, y_{h}^{0} \in V^{h}$ is the approximation of $y^{0}$.

Since this is a finite dimensional linear control problem and the reduced objective function is convex, we can easily prove that the above problem (3.7)-(3.8) has a unique solution $\left(y_{h}, u_{h}\right) \in W^{h} \times U_{a d}^{h}$. 
By applying [24] again we can show that a pair $\left(y_{h}, u_{h}\right) \in W^{h} \times U_{a d}^{h}$ is a solution of (3.7)-(3.8), if and only if there exists a costate $p_{h} \in W^{h}$ such that the triple $\left(y_{h}, p_{h}, u_{h}\right)$ satisfies the following optimality conditions, which we will label (OCP - OPT) ${ }^{h}$ :

$$
\begin{gathered}
\left(\frac{\partial y_{h}}{\partial t}, w_{h}\right)+a\left(y_{h}, w_{h}\right)+\int_{0}^{t} c\left(t, \tau ; y_{h}(\tau), w_{h}(t)\right) d \tau=\left(f+B u_{h}, w_{h}\right), \quad \forall w_{h} \in V^{h}, \\
\left.y_{h}\right|_{t=0}=y_{h^{\prime}}^{0} \\
-\left(q_{h}, \frac{\partial p_{h}}{\partial t}\right)+a\left(q_{h}, p_{h}\right)+\int_{t}^{T} c\left(\tau, t ; q_{h}, p_{h}(\tau)\right) d \tau=\left(y_{h}-z_{d}, q_{h}\right), \quad \forall q_{h} \in V^{h}, \\
\left.p_{h}\right|_{t=T}=0, \\
\int_{0}^{T}\left(h^{\prime}\left(u_{h}\right)+B^{*} p_{h}, v_{h}-u_{h}\right)_{U} d t \geqslant 0, \quad \forall v_{h} \in U_{a d}^{h} .
\end{gathered}
$$

The optimality conditions in (3.9)-(3.11) are the semidiscrete approximation to the problem (3.1)-(3.3).

\section{A Posteriori Error Estimates for First-Order Derivatives}

Adaptive finite element approximation has been found very useful in computing optimal control, as mentioned in Introduction. It uses an a posteriori error indicator to guide the mesh refinement procedure. Furthermore it has been recently found that for constrained control problems, different adaptive meshes are often needed for the control and the states; see [27]. Using different adaptive meshes for the control and the state allows very coarse meshes to be used in solving the state and costate equations. Thus much computational work can be saved since one of the major computational loads is to solve the state and costate equations repeatedly. In this section, we derive the upper a posteriori error estimates for the optimal control problem allowing different meshes to be used for the states and the control. follows:

For simplicity, we will only consider the case of quadratic objective functionals as

$$
J(u, y)=\int_{0}^{T}(g(y)+h(u)) d t=\left\{\frac{1}{2} \int_{0}^{T}\left\|y-z_{d}\right\|_{0, \Omega}^{2}+\frac{\beta}{2} \int_{0}^{T}\|u\|_{0, \Omega_{u}}^{2}\right\} .
$$

Here

$$
\begin{gathered}
g(y)=\frac{1}{2} \int_{0}^{T}\left\|y-z_{d}\right\|_{0, \Omega^{\prime}}^{2} \\
h(u)=\frac{\beta}{2} \int_{0}^{T}\|u\|_{0, \Omega_{u^{\prime}}}^{2}
\end{gathered}
$$


where $r$ is a positive regularity constant. By differential theory, we have

$$
h^{\prime}(u)(v)=(\beta u, v)
$$

Then the inequality (3.3) and (3.11) in optimality condition can be restated as follows:

$$
\begin{gathered}
\int_{0}^{T}\left(\beta u+B^{*} p, v-u\right)_{U} d t \geqslant 0, \quad \forall v \in U_{a d} \\
\int_{0}^{T}\left(\beta u_{h}+B^{*} p_{h}, v_{h}-u_{h}\right)_{U} d t \geqslant 0, \quad \forall v_{h} \in U_{a d}^{h} .
\end{gathered}
$$

In this paper, we consider the integration obstacle type control constraint:

$$
U_{a d}=\left\{v \in X ; \int_{\Omega_{u}} v \geqslant 0, t \in[0, T]\right\}
$$

By computation and from [28], we know that the solutions of inequality (4.4) and (4.5) yield

$$
\beta u=-B^{*} p+\max \left\{0, \frac{\int_{\Omega_{U}} B^{*} p}{\int_{\Omega_{u}} 1}\right\}, \quad \beta u_{h}=P_{h}\left(-B^{*} p_{h}+\max \left\{0, \frac{\int_{\Omega_{U}} B^{*} p_{h}}{\int_{\Omega_{U}} 1}\right\}\right)
$$

where $P_{h}$ is the $L^{2}$-projection from $L^{2}(\Omega)$ to $U^{h}$.

And we will consider the special case of the differential operator of $\alpha$ and $\gamma$ :

$$
\alpha y=-\operatorname{div}(A \nabla y), \quad \gamma(t, \tau) y=-\operatorname{div}(C(t, \tau) \nabla y)
$$

where $A=A(x)=\left(a_{i, j}(\cdot)\right)_{n \times n} \in\left(C^{\infty}(\bar{\Omega})\right)^{n \times n}$, such that there are constants $c>0$ satisfying

$$
X^{t} A X \geqslant c\|X\|_{R^{n}}^{2}, \quad \forall X \in R^{n}
$$

and $C=C(x, t, \tau)=\left(c_{i, j}(x, t, \tau)\right)_{n \times n} \in\left(C^{\infty}\left(0, T ; L^{2}(\bar{\Omega})\right)^{n \times n}\right)$.

In this case, we have the following bilinear form

$$
\begin{gathered}
a(z, w)=(\alpha z, w)=(-\operatorname{div}(A \nabla z), w)=(A \nabla z, \nabla w), \\
c(t, \tau ; z, w)=(\gamma(t, \tau) z, w)=(-\operatorname{div}(C(t, \tau) \nabla z), w)=(C(t, \tau) \nabla z, \nabla w) .
\end{gathered}
$$




\subsection{Main Results}

We first state the main results of this section.

Theorem 4.1. Let $(y, u)$ and $\left(y_{h}, u_{h}\right)$ be the solutions of $(O C P)$ and $(O C P)^{h}$, respectively. Let $p$ and $p_{h}$ be the solution of the costate equations (3.2) and (3.10). Then there hold the a posteriori error estimates

$$
\begin{aligned}
& \left\|u-u_{h}\right\|_{L^{2}\left(0, T ; L^{2}(\Omega u)\right)}^{2}+\left\|y-y_{h}\right\|_{L^{\infty}\left(0, T ; L^{2}(\Omega)\right)}^{2}+\left\|y-y_{h}\right\|_{L^{2}\left(0, T ; H^{1}(\Omega)\right)}^{2}+\left\|p-p_{h}\right\|_{L^{\infty}\left(0, T ; L^{2}(\Omega)\right)}^{2} \\
& \quad+\left\|p-p_{h}\right\|_{L^{2}\left(0, T ; H^{1}(\Omega)\right)}^{2} \leqslant C \sum_{i=1}^{6} \eta_{i^{2}}^{2}
\end{aligned}
$$

where $\eta_{1}^{2}, \ldots, \eta_{6}^{2}$ is defined as follows:

$$
\begin{aligned}
& \eta_{1}^{2}=\int_{0}^{T}\left\{\sum_{\tau_{U}} \int_{\tau_{U}}\left(B^{*} p_{h}-P_{h}\left(B^{*} p_{h}\right)\right)^{2}\right\} d t, \\
& \eta_{2}^{2}=\int_{0}^{T}\left\{\sum_{\tau} h_{\tau}^{2} \int_{\tau}\left(\frac{\partial}{\partial t} p_{h}+\operatorname{div}\left(A^{*} \nabla p_{h}\right)+\int_{t}^{T} \operatorname{div}\left(C^{*}(\tau, t) \nabla p_{h}(\tau)\right) d \tau+y_{h}-z_{d}\right)^{2} d \tau\right\} d t, \\
& \eta_{3}^{2}=\int_{0}^{T} \sum_{\tau} h_{l} \int_{\partial \tau}\left[\left(A^{*} \nabla p_{h}\right) \cdot n+\int_{t}^{T}\left(C^{*}(\tau, t) \nabla p_{h}(\tau)\right) \cdot n d \tau\right]^{2} d l d t, \\
& \eta_{4}^{2}=\int_{0}^{T}\left\{\sum_{\tau} h_{\tau}^{2} \int_{\tau}\left(\frac{\partial}{\partial t} y_{h}-\operatorname{div}\left(A \nabla y_{h}\right)-\int_{0}^{t} \operatorname{div}\left(C(t, \tau) \nabla y_{h}(\tau)\right) d \tau-f-B u_{h}\right)^{2}\right\} d t, \\
& \eta_{5}^{2}=\int_{0}^{T} \sum_{\tau} h_{l} \int_{\partial \tau}\left[\left(A \nabla y_{h}\right) \cdot n+\int_{0}^{t}\left(C(t, \tau) \nabla y_{h}(\tau)\right) \cdot n d \tau\right]^{2} d l d t, \\
& \eta_{6}^{2}=\left\|y_{0}^{h}-y_{0}\right\|_{L^{2}(\Omega)}^{2}
\end{aligned}
$$

where $l$ is a face of an element $\tau, h_{l}$ is the maximum diameter of $l,\left[\nabla p_{h} \cdot n\right]$ and $\left[\nabla y_{h} \cdot n\right]$ are the normal derivative jumps over the interior face $l$, defined by

$$
\begin{aligned}
{\left[\nabla p_{h} \cdot n\right]_{l} } & =\left(\left.\nabla p_{h} h\right|_{\tau_{l}^{1}}-\left.\nabla p_{h}\right|_{\tau_{l}^{2}}\right) \cdot n, \\
{\left[\nabla y_{h} \cdot n\right]_{l} } & =\left(\left.\nabla y_{h}\right|_{\tau_{l}^{1}}-\left.\nabla y_{h}\right|_{\tau_{l}^{2}}\right) \cdot n,
\end{aligned}
$$

where $n$ is the unit normal vector on $l=\tau_{l}^{1} \cap \tau_{l}^{2}$ outwards $\tau_{l}^{1}$. For later convenience, one defines $\left[\nabla p_{h} \cdot n\right]_{l}=0$ and $\left[\nabla y_{h} \cdot n\right]_{l}=0$ when $l \subset \partial \Omega$. 
In the following subsections, we will prove Theorem 4.1. To this end, we first give some lemmas in the following subsection. The proofs of Theorem 4.1 are put in the last subsection.

\subsection{Some Lemmas}

We have the following.

Lemma 4.2. Let $(y, u)$ and $\left(y_{h}, u_{h}\right)$ be the solutions of $(O C P)$ and $(O C P)^{h}$, respectively. Let $p$ and $p_{h}$ be the solution of the costate equations (3.2) and (3.10). Then

$$
\left\|u-u_{h}\right\|_{L^{2}\left(0, T ; L^{2}\left(\Omega_{u}\right)\right)}^{2} \leqslant C \eta_{1}^{2}+C\left\|p_{h}-p\left(u_{h}\right)\right\|_{L^{2}\left(0, T ; L^{2}(\Omega)\right)}^{2}
$$

where $p\left(u_{h}\right)$ is defined by the following system:

$$
\begin{gathered}
\left(\frac{\partial}{\partial t} y\left(u_{h}\right), \omega\right)+a\left(y\left(u_{h}\right), \omega\right)+\int_{0}^{t} c\left(t, \tau ; y\left(u_{h}\right)(\tau), \omega(t)\right) d \tau=\left(f+B u_{h}, \omega\right), \quad \forall \omega \in V \\
y\left(u_{h}\right)(0)=y_{0}^{h}(x), \quad x \in \Omega \\
-\left(q, \frac{\partial}{\partial t} p\left(u_{h}\right)\right)+a\left(q, p\left(u_{h}\right)\right)+\int_{t}^{T} c\left(\tau, t ; q(t), p\left(u_{h}\right)(\tau)\right) d \tau=\left(y\left(u_{h}\right)-z_{d}, q\right), \quad \forall q \in V .
\end{gathered}
$$

Proof. It follows from (4.4) that we have

$$
\left(\beta u, u-u_{h}\right)_{U} \leqslant-\left(B^{*} p, u-u_{h}\right)_{U}
$$

Then by (4.5) and (4.18)

$$
\begin{aligned}
\beta\left\|u-u_{h}\right\|_{L^{2}\left(0, T ; L^{2}\left(\Omega_{U}\right)\right)}^{2}= & \int_{0}^{T}\left[\beta\left(u, u-u_{h}\right)_{U}-\beta\left(u_{h}, u-u_{h}\right)_{U}\right] d t \\
\leqslant & \int_{0}^{T}\left[-\left(B^{*} p, u-u_{h}\right)_{U}-\left(\beta u_{h}, u-u_{h}\right)_{U}\right] d t=\int_{0}^{T}-\left(B^{*} p+\beta u_{h}, u-u_{h}\right)_{U} d t \\
= & -\int_{0}^{T}\left(B^{*} p_{h}+\beta u_{h}, u-v_{h}\right)_{U} d t-\int_{0}^{T}\left(B^{*} p_{h}+\beta u_{h}, v_{h}-u_{h}\right)_{U} d t \\
& +\int_{0}^{T}\left(B^{*} p_{h}-B^{*} p\left(u_{h}\right), u-u_{h}\right)_{U} d t+\int_{0}^{T}\left(B^{*} p\left(u_{h}\right)-B^{*} p, u-u_{h}\right)_{U} d t
\end{aligned}
$$




$$
\begin{aligned}
& \leqslant \inf _{v_{h} \in U_{a d}^{h}} \int_{0}^{T}\left(B^{*} p_{h}+\beta u_{h}, v_{h}-u\right)_{U} d t \\
& \quad+\int_{0}^{T}\left(B^{*}\left(p_{h}-p\left(u_{h}\right)\right), u-u_{h}\right)_{U} d t+\int_{0}^{T}\left(B^{*}\left(p\left(u_{h}\right)-p\right), u-u_{h}\right)_{U} d t \\
& =I_{1}+I_{2}+I_{3} .
\end{aligned}
$$

Since $P_{h}$ is the $L^{2}$-projection, then, for any $v \in U_{a d}$, we have

$$
\int_{\Omega_{u}}\left(P_{h} v-v\right) \phi=0, \quad \forall \phi \in X^{h}, t \in(0, T]
$$

Note that $\int_{\Omega_{u}} v \geqslant 0$ and $\int_{\Omega_{u}}\left(P_{h} v-v\right)=0$. Then we have $\int_{\Omega_{u}} P_{h} v \geqslant 0$, thus $P_{h} v \in U_{a d}^{h}$. So that we can take $v_{h}=P_{h} u$ in $I_{1}$ and by (4.7), we have

$$
\begin{aligned}
I_{1} & \leqslant \int_{0}^{T}\left(B^{*} p_{h}+\beta u_{h}, P_{h} u-u\right)_{U} d t \\
& =\int_{0}^{T}\left\{\sum_{\tau_{U}} \int_{\tau_{U}}\left[P_{h}\left(-B^{*} p_{h}+\max \left\{0, \frac{\int_{\Omega_{U}} B^{*} p_{h}}{\int_{\Omega_{U}} 1}\right\}\right)+B^{*} p_{h}\right]\left(P_{h} u-u\right)\right\} d t \\
& \leqslant \int_{0}^{T}\left\{\sum_{\tau_{U}} \int_{\tau_{U}}\left(-P_{h}\left(B^{*} p_{h}\right)+B^{*} p_{h}\right)\left(P_{h} u-u\right)\right\} d t \\
& =\int_{0}^{T}\left\{\sum_{\tau_{U}} \int_{\tau_{U}}\left(-P_{h}\left(B^{*} p_{h}\right)+B^{*} p_{h}\right)\left(P_{h}\left(u-u_{h}\right)-\left(u-u_{h}\right)\right)\right\} d t \\
& \leqslant C(\delta) \int_{0}^{T}\left\{\sum_{\tau_{U}} \int_{\tau_{U}}\left(-P_{h}\left(B^{*} p_{h}\right)+B^{*} p_{h}\right)^{2}\right\} d t+\delta\left\|u-u_{h}\right\|_{L^{2}\left(0, T ; L^{2}\left(\Omega_{U}\right)\right)}^{2} \\
& =C \eta_{1}^{2}+\delta\left\|u-u_{h}\right\|_{L^{2}\left(0, T ; L^{2}\left(\Omega_{u}\right)\right)^{\prime}}^{2} \\
I_{2} \leqslant & C\left\|p_{h}-p\left(u_{h}\right)\right\|_{L^{2}\left(0, T ; L^{2}(\Omega)\right)}^{2}+\delta\left\|u-u_{h}\right\|_{L^{2}\left(0, T ; L^{2}\left(\Omega_{U}\right)\right)^{2}}^{2}
\end{aligned}
$$

From (4.15) and (3.1), we have for $t \in(0, T]$

$$
\begin{gathered}
\left(\frac{\partial}{\partial t}\left(y-y\left(u_{h}\right)\right), \omega\right)+a\left(y-y\left(u_{h}\right), w\right)+\int_{0}^{t} c\left(t, \tau ;\left(y-y\left(u_{h}\right)\right)(\tau), \omega(t)\right) d \tau \\
=\left(B\left(u-u_{h}\right), \omega\right), \quad \forall \omega \in V
\end{gathered}
$$


and from (4.17) and (3.2)

$$
\begin{aligned}
-(q, & \left.\frac{\partial}{\partial t}\left(p-p\left(u_{h}\right)\right)\right)+a\left(q, p-p\left(u_{h}\right)\right)+\int_{t}^{T} c\left(\tau, t ; q(t),\left(p-p\left(u_{h}\right)\right)(\tau)\right) d \tau \\
= & \left(y-y\left(u_{h}\right), q\right), \quad \forall q \in V .
\end{aligned}
$$

Then from (4.23), (4.24) and integrating by part

$$
\begin{aligned}
& I_{3}= \int_{0}^{T}\left(p\left(u_{h}\right)-p, B\left(u-u_{h}\right)\right)_{U} d t \\
&= \int_{0}^{T}\left[\left(\frac{\partial}{\partial t}\left(y-y\left(u_{h}\right)\right), p\left(u_{h}\right)-p\right)+a\left(y-y\left(u_{h}\right), p\left(u_{h}\right)-p\right)\right. \\
&\left.\quad \quad \int_{0}^{t} c\left(t, \tau ;\left(y-y\left(u_{h}\right)\right)(\tau),\left(p\left(u_{h}\right)-p\right)(t)\right) d \tau\right] d t \\
&=\int_{0}^{T}\left[-y-y\left(u_{h}\right), \frac{\partial}{\partial t}\left(p-p\left(u_{h}\right)\right)+a\left(y-y\left(u_{h}\right), p\left(u_{h}\right)-p\right)\right. \\
&\left.\quad+\int_{t}^{T} c\left(\tau, t ;\left(y-y\left(u_{h}\right)\right)(t),\left(p\left(u_{h}\right)-p\right)(\tau)\right) d \tau\right] d t \\
&=\int_{0}^{T}-\left(y-y\left(u_{h}\right), y-y\left(u_{h}\right)\right) d t \leqslant 0 .
\end{aligned}
$$

Following from (4.21)-(4.25), let $\delta$ be small enough:

$$
\left\|u-u_{h}\right\|_{L^{2}\left(0, T ; L^{2}\left(\Omega_{u}\right)\right)}^{2} \leqslant C \eta_{1}^{2}+C\left\|p_{h}-p\left(u_{h}\right)\right\|_{L^{2}\left(0, T ; L^{2}(\Omega)\right)}^{2} .
$$

The proof of Lemma 4.2 is completed.

Lemma 4.3. Let $(y, u)$ and $\left(y_{h}, u_{h}\right)$ be the solutions of $(O C P)$ and $(O C P)^{h}$, respectively. Let $p$ and $p_{h}$ be the solution of the costate equations (3.2) and (3.10). Then there hold the a posteriori error estimates

$$
\begin{aligned}
& \left\|y_{h}-y\left(u_{h}\right)\right\|_{L^{\infty}\left(0, T ; L^{2}(\Omega)\right)}^{2}+\left\|y_{h}-y\left(u_{h}\right)\right\|_{L^{2}\left(0, T ; H^{1}(\Omega)\right)}^{2}+\left\|p_{h}-p\left(u_{h}\right)\right\|_{L^{\infty}\left(0, T ; L^{2}(\Omega)\right)}^{2} \\
& \quad+\left\|p_{h}-p\left(u_{h}\right)\right\|_{L^{2}\left(0, T ; H^{1}(\Omega)\right)}^{2} \leqslant C \sum_{i=2}^{6} \eta_{i}^{2} .
\end{aligned}
$$

Proof. Let

$$
\left\langle E\left(u_{h}\right), v\right\rangle=-\left(v, \frac{\partial}{\partial t}\left(p_{h}-p\left(u_{h}\right)\right)\right)+a\left(v, p_{h}-p\left(u_{h}\right)\right)+\int_{t}^{T} c\left(\tau, t ; v(t),\left(p_{h}-p\left(u_{h}\right)\right)(\tau)\right) d \tau
$$


and $\pi_{h}$ be the average interpolation operator defined as in [27] and $e=p_{h}-p\left(u_{h}\right)$. Then from (3.10) and (4.17)

$$
\begin{aligned}
& -\left(q_{h}, \frac{\partial}{\partial t}\left(p_{h}-p\left(u_{h}\right)\right)\right)+a\left(q_{h}, p_{h}-p\left(u_{h}\right)\right)+\int_{t}^{T} c\left(\tau, t ; q_{h}(t),\left(p_{h}-p\left(u_{h}\right)\right)(\tau)\right) d \tau \\
& =\left(y_{h}-y\left(u_{h}\right), q_{h}\right), \quad \forall q_{h} \in V^{h} .
\end{aligned}
$$

So we have

$$
\begin{aligned}
-(v, & \left.\frac{\partial}{\partial t}\left(p_{h}-p\left(u_{h}\right)\right)\right)+a\left(v, p_{h}-p\left(u_{h}\right)\right)+\int_{t}^{T} c\left(\tau, t ; v(t),\left(p_{h}-p\left(u_{h}\right)\right)(\tau)\right) d \tau \\
= & -\left(v-\pi_{h} v, \frac{\partial}{\partial t} p_{h}\right)+a\left(v-\pi_{h} v, p_{h}\right)+\int_{t}^{T} c\left(\tau, t ;\left(v-\pi_{h} v\right)(t), p_{h}(\tau)\right) d \tau \\
& +\left(v-\pi_{h} v, \frac{\partial}{\partial t} p\left(u_{h}\right)\right)-a\left(v-\pi_{h} v, p\left(u_{h}\right)\right) \\
& -\int_{t}^{T} c\left(\tau, t ;\left(v-\pi_{h} v\right)(t), p\left(u_{h}\right)(\tau)\right) d \tau+\left(y_{h}-y\left(u_{h}\right), \pi_{h} v\right) \\
\leqslant & \left\{\sum_{\tau} \int_{\tau} h_{\tau}^{2}\left(-\frac{\partial}{\partial t} p_{h}-\operatorname{div}\left(A^{*} \nabla p_{h}\right)-\int_{t}^{T} \operatorname{div}\left(C^{*}(\tau, t) \nabla p_{h}(\tau)\right) d \tau-y_{h}+z_{d}\right)^{2}\right. \\
& \left.+\sum_{\tau} \int_{\partial \tau} h_{l}\left[\left(A^{*} \nabla p_{h}\right) \cdot n+\int_{t}^{T}\left(C^{*}(\tau, t) \nabla p_{h}(\tau)\right) \cdot n d \tau\right]^{2}\right\}^{1 / 2}\|v\|_{1, \Omega}+\left(y_{h}-y\left(u_{h}\right), v\right) .
\end{aligned}
$$

By letting $v=p_{h}-p\left(u_{h}\right)$ in (4.30) and from (2.2), we have

$$
\begin{aligned}
& -\frac{1}{2} \frac{d}{d t}\left\|p_{h}-p\left(u_{h}\right)\right\|_{0, \Omega}^{2}+c\left\|p_{h}-p\left(u_{h}\right)\right\|_{1, \Omega}^{2} \\
& \leqslant\left\{\sum_{\tau} \int_{\tau} h_{\tau}^{2}\left(-\frac{\partial}{\partial t} p_{h}-\operatorname{div}\left(A^{*} \nabla p_{h}\right)-\int_{t}^{T} \operatorname{div}\left(C^{*}(\tau, t) \nabla p_{h}(\tau)\right) d \tau-y_{h}+z_{d}\right)^{2}\right. \\
& \left.\quad+\sum_{\tau} \int_{\partial \tau} h_{l}\left[\left(A^{*} \nabla p_{h}\right) \cdot n+\int_{t}^{T}\left(C^{*}(\tau, t) \nabla p_{h}(\tau)\right) \cdot n d \tau\right]^{2}\right\}^{1 / 2}\left\|p_{h}-p\left(u_{h}\right)\right\|_{1, \Omega} \\
& \quad+\left(y_{h}-y\left(u_{h}\right),\left(p_{h}-p\left(u_{h}\right)\right)\right)-\int_{t}^{T} c\left(\tau, t ;\left(p_{h}-p\left(u_{h}\right)\right)(t),\left(p_{h}-p\left(u_{h}\right)\right)(\tau)\right) d \tau .
\end{aligned}
$$


Integrating time from $t$ to $T$ in (4.31) and by Schwartz inequality, Lemmas 3.3 and 3.4, we have

$$
\begin{aligned}
& \frac{1}{2}\left\|p_{h}-p\left(u_{h}\right)\right\|_{0, \Omega}^{2}+c \int_{t}^{T}\left\|p_{h}-p\left(u_{h}\right)\right\|_{1, \Omega}^{2} d \tau \\
& \leqslant \int_{t}^{T} \sum_{\tau} h_{\tau}^{2} \int_{\tau}\left(\frac{\partial}{\partial t} p_{h}+\operatorname{div}\left(A^{*} \nabla p_{h}\right)+\int_{\tau}^{T} \operatorname{div}\left(C^{*}(s, \tau) \nabla p_{h}(s)\right) d s+y_{h}-z_{d}\right)^{2} d \tau \\
& \quad+\int_{t}^{T} \sum_{\tau} h_{l} \int_{\partial \tau}\left[\left(A^{*} \nabla p_{h}\right) \cdot n+\int_{\tau}^{T}\left(C^{*}(s, \tau) \nabla p_{h}(s)\right) \cdot n d s\right]^{2} d \tau+\delta \int_{t}^{T}\left\|p_{h}-p\left(u_{h}\right)\right\|_{1, \Omega}^{2} d \tau \\
& \quad+C \int_{t}^{T}\left\|y_{h}-y\left(u_{h}\right)\right\|_{0, \Omega}^{2} d \tau+C \int_{t}^{T} \int_{\tau}^{T}\left\|\left(p_{h}-p\left(u_{h}\right)\right)(s)\right\|_{1, \Omega}^{2} d s d \tau .
\end{aligned}
$$

Letting $\delta$ be small enough, we obtain

$$
\begin{aligned}
& \int_{t}^{T}\left\|p_{h}-p\left(u_{h}\right)\right\|_{1, \Omega}^{2} d \tau \\
& \leqslant C \int_{t}^{T} \sum_{\tau} h_{\tau}^{2} \int_{\tau}\left(\frac{\partial}{\partial t} p_{h}+\operatorname{div}\left(A^{*} \nabla p_{h}\right)+\int_{\tau}^{T} \operatorname{div}\left(C^{*}(s, \tau) \nabla p_{h}(s)\right) d s+y_{h}-z_{d}\right)^{2} d \tau \\
& \quad+C \int_{t}^{T} \sum_{\tau} h_{l} \int_{\partial \tau}\left[\left(A^{*} \nabla p_{h}\right) \cdot n+\int_{\tau}^{T}\left(C^{*}(s, \tau) \nabla p_{h}(s)\right) \cdot n d s\right]^{2} d \tau \\
& \quad+C \int_{t}^{T}\left\|y_{h}-y\left(u_{h}\right)\right\|_{0, \Omega}^{2} d \tau+C \int_{t}^{T} \int_{\tau}^{T}\left\|\left(p_{h}-p\left(u_{h}\right)\right)(s)\right\|_{1, \Omega}^{2} d s d \tau .
\end{aligned}
$$

By Gronwall inequality and (4.30)-(4.33)

$$
\left\|p_{h}-p\left(u_{h}\right)\right\|_{L^{2}\left(0, T ; H^{1}(\Omega)\right)}^{2} \leqslant C \eta_{2}^{2}+C \eta_{3}^{2}+C\left\|y_{h}-y\left(u_{h}\right)\right\|_{L^{2}\left(0, T ; L^{2}(\Omega)\right)}^{2}
$$

Similarly, we have

$$
\begin{aligned}
\left\|p_{h}-p\left(u_{h}\right)\right\|_{L^{\infty}\left(0, T ; L^{2}(\Omega)\right)}^{2} \leqslant & C\left(\eta_{2}^{2}+\eta_{3}^{2}+\left\|y_{h}-y\left(u_{h}\right)\right\|_{L^{2}\left(0, T ; L^{2}(\Omega)\right)}^{2}\right) \\
& +C \int_{0}^{T} \int_{t}^{T}\left\|\left(p_{h}-p\left(u_{h}\right)\right)(\tau)\right\|_{1, \Omega}^{2} d \tau d t \\
\leqslant & C \eta_{2}^{2}+C \eta_{3}^{2}+C\left\|y_{h}-y\left(u_{h}\right)\right\|_{L^{2}\left(0, T ; L^{2}(\Omega)\right)}^{2} .
\end{aligned}
$$


Then from (4.30), (4.34), and (4.35)

$$
\begin{aligned}
& \left\|\frac{\partial}{\partial t}\left(p_{h}-p\left(u_{h}\right)\right)\right\|_{L^{2}\left(0, T ; H^{-1}(\Omega)\right)}=\sup _{v \in L^{2}\left(0, T ; H_{0}^{1}(\Omega)\right)} \frac{\int_{0}^{T}\left((\partial / \partial t)\left(p_{h}-p\left(u_{h}\right)\right), v\right)}{\|v\|_{L^{2}\left(0, T ; H^{1}(\Omega)\right)}} \\
& \quad=\sup _{v \in L^{2}\left(0, T ; H_{0}^{1}(\Omega)\right)} \frac{\int_{0}^{T}\left(\left\langle-E\left(u_{h}\right), v\right\rangle+a\left(v, p_{h}-p\left(u_{h}\right)\right)+\int_{t}^{T} c\left(\tau, t ; v(t),\left(p_{h}-p\left(u_{h}\right)\right)(\tau)\right) d \tau\right) d t}{\|v\|_{L^{2}\left(0, T ; H^{1}(\Omega)\right)}} \\
& \quad \leq C \eta_{2}+C \eta_{3}+C\left\|y_{h}-y\left(u_{h}\right)\right\|_{L^{2}\left(0, T ; L^{2}(\Omega)\right)}+C\left\|p_{h}-p\left(u_{h}\right)\right\|_{L^{2}\left(0, T ; H^{1}(\Omega)\right)} \\
& \quad \leq C \eta_{2}+C \eta_{3}+C\left\|y_{h}-y\left(u_{h}\right)\right\|_{L^{2}\left(0, T ; L^{2}(\Omega)\right)} .
\end{aligned}
$$

Similarly by analysis of $\left\|y_{h}-y\left(u_{h}\right)\right\|_{L^{2}\left(0, T ; H^{1}(\Omega)\right)}$, we let

$$
\left\langle Q\left(u_{h}\right), v\right\rangle=\left(\frac{\partial}{\partial_{t}}\left(y_{h}-y\left(u_{h}\right)\right), v\right)+a\left(y_{h}-y\left(u_{h}\right), v\right)+\int_{0}^{t} c\left(t, \tau ;\left(y_{h}-y\left(u_{h}\right)\right)(\tau), v(t)\right) d \tau
$$

By (3.9) and (4.15)

$$
\begin{aligned}
& \left(\omega_{h}, \frac{\partial}{\partial t}\left(y_{h}-y\left(u_{h}\right)\right)\right)+a\left(y_{h}-y\left(u_{h}\right), \omega_{h}\right)+\int_{0}^{t} c\left(t, \tau ;\left(y_{h}-y\left(u_{h}\right)\right)(\tau), \omega_{h}(t)\right) d \tau \\
& =0, \quad \forall \omega_{h} \in V^{h}
\end{aligned}
$$

So

$$
\begin{aligned}
\left(\frac{\partial}{\partial t}\left(y_{h}-y\left(u_{h}\right)\right), v\right)+a\left(y_{h}-y\left(u_{h}\right), v\right)+\int_{0}^{t} c\left(t, \tau ;\left(y_{h}-y\left(u_{h}\right)\right)(\tau), v(t)\right) d \tau \\
=\left(\frac{\partial}{\partial t} y_{h}, v-\pi_{h} v\right)+a\left(y_{h}, v-\pi_{h} v\right)+\int_{0}^{t} c\left(t, \tau ; y_{h}(\tau),\left(v-\pi_{h} v\right)(t)\right) d \tau-\left(f+B u_{h}, v-\pi_{h} v\right) \\
\leqslant\left\{\sum_{\tau} \int_{\tau} h_{\tau}^{2}\left(\frac{\partial}{\partial t} y_{h}-\operatorname{div}\left(A \nabla y_{h}\right)-\int_{0}^{t} \operatorname{div}\left(C(t, \tau) \nabla y_{h}\right) d \tau-f-B u_{h}\right)^{2}\right. \\
\left.\quad+\sum_{\tau} \int_{\partial \tau} h_{l}\left[\left(A \nabla y_{h}\right) \cdot n+\int_{0}^{t}\left(C(t, \tau) \nabla y_{h}\right) \cdot n d \tau\right]^{2}\right\}^{1 / 2}\|v\|_{1, \Omega} .
\end{aligned}
$$


By letting $v=y_{h}-y\left(u_{h}\right)$ and applying Swartz inequality, we have

$$
\begin{aligned}
& \frac{1}{2} \frac{d}{d t}\left\|y_{h}-y\left(u_{h}\right)\right\|_{0, \Omega}^{2}+c\left\|y_{h}-y\left(u_{h}\right)\right\|_{1, \Omega}^{2} \\
& \leqslant \sum_{\tau} \int_{\tau} h_{\tau}^{2}\left(\frac{\partial}{\partial t} y_{h}-\operatorname{div}\left(A \nabla y_{h}\right)-\int_{0}^{t} \operatorname{div}\left(C(t, \tau) \nabla y_{h}\right) d \tau-f-B u_{h}\right)^{2} \\
& \quad+\sum_{\tau} \int_{\partial \tau} h_{l}\left[\left(A \nabla y_{h}\right) \cdot n+\int_{0}^{t}\left(C(t, \tau) \nabla y_{h}\right) \cdot n d \tau\right]^{2} \\
& +\delta\left\|y_{h}-y\left(u_{h}\right)\right\|_{1, \Omega}^{2}-\int_{0}^{t} c\left(t, \tau ;\left(y_{h}-y\left(u_{h}\right)\right)(\tau), y_{h}-y\left(u_{h}\right)(t)\right) d \tau .
\end{aligned}
$$

By integrating time from 0 to $t$ in (4.40)

$$
\begin{aligned}
& \left\|y_{h}-y\left(u_{h}\right)\right\|_{0, \Omega}^{2}+c \int_{0}^{t}\left\|y_{h}-y\left(u_{h}\right)\right\|_{1, \Omega}^{2} d \tau \\
& \leqslant C\left\{\int_{0}^{t} \sum_{\tau} h_{\tau}^{2} \int_{\tau}\left(\frac{\partial}{\partial t} y_{h}-\operatorname{div}\left(A \nabla y_{h}\right)-\int_{0}^{\tau} \operatorname{div}\left(C(\tau, s) \nabla y_{h}\right) d s-f-B u_{h}\right)^{2} d \tau\right. \\
& \left.\quad+\int_{0}^{t} \sum_{\tau} h_{l} \int_{\partial \tau}\left[\left(A \nabla y_{h}\right) \cdot n+\int_{0}^{\tau}\left(C(\tau, s) \nabla y_{h}\right) \cdot n d s\right]^{2} d t\right\}+\delta \int_{0}^{t}\left\|y_{h}-y\left(u_{h}\right)\right\|_{1, \Omega}^{2} d \tau \\
& \quad+C \int_{0}^{t} \int_{0}^{\tau}\left\|y_{h}-y\left(u_{h}\right)\right\|_{1, \Omega}^{2} d s d \tau+C\left\|y_{0}-y_{0}^{h}\right\|_{0, \Omega}^{2} \cdot
\end{aligned}
$$

Since $\delta$ is small, then from (4.41) and Gronwall inequality we have

$$
\begin{aligned}
& \int_{0}^{t}\left\|y_{h}-y\left(u_{h}\right)\right\|_{1, \Omega}^{2} d t \\
& \leqslant C \int_{0}^{t} \sum_{\tau} h_{\tau}^{2} \int_{\tau}\left(\frac{\partial}{\partial t} y_{h}-\operatorname{div}\left(A \nabla y_{h}\right)-\int_{0}^{\tau} \operatorname{div}\left(C(\tau, s) \nabla y_{h}\right) d s-f-B u_{h}\right)^{2} d \tau \\
& \quad+C \int_{0}^{t} \sum_{\tau} h_{l} \int_{\partial \tau}\left[\left(A \nabla y_{h}\right) \cdot n+\int_{0}^{\tau}\left(C(\tau, s) \nabla y_{h}\right) \cdot n d s\right]^{2} d t+C\left\|y_{0}-y_{0}^{h}\right\|_{0, \Omega}^{2}
\end{aligned}
$$

and we obtain

$$
\begin{aligned}
& \left\|y_{h}-y\left(u_{h}\right)\right\|_{L^{2}\left(0, T ; H^{1}(\Omega)\right)}^{2} \leqslant C\left(\eta_{4}^{2}+\eta_{5}^{2}+\eta_{6}^{2}\right), \\
& \left\|y_{h}-y\left(u_{h}\right)\right\|_{L^{\infty}\left(0, T ; L^{2}(\Omega)\right)}^{2} \leqslant C\left(\eta_{4}^{2}+\eta_{5}^{2}+\eta_{6}^{2}\right) .
\end{aligned}
$$


In the same way of getting (4.36), we also have

$$
\left\|\frac{\partial}{\partial t}\left(y_{h}-y\left(u_{h}\right)\right)\right\|_{L^{2}\left(0, T ; H^{-1}(\Omega)\right)}^{2} \leqslant C\left(\eta_{4}^{2}+\eta_{5}^{2}+\eta_{6}^{2}\right) .
$$

Then the desired results (4.27) follow from (4.34)-(4.36) and (4.43)-(4.44).

\subsection{Proof of Theorem 4.1}

By Lemmas 4.2 and 4.3 , we prove Theorem 4.1 in the following.

Proof. By using the triangle inequality, Lemmas 4.2 and 4.3, and from (4.29) and (4.38), [17$19]$, using the following stability results

$$
\begin{aligned}
\left\|y-y\left(u_{h}\right)\right\|_{L^{\infty}\left(0, T ; L^{2}(\Omega)\right)}^{2}+\left\|y-y\left(u_{h}\right)\right\|_{L^{2}\left(0, T ; H^{1}(\Omega)\right)}^{2} & \leqslant C\left\|u-u_{h}\right\|_{L^{2}\left(0, T ; L^{2}\left(\Omega_{U}\right)\right)^{\prime}}^{2} \\
\left\|p-p\left(u_{h}\right)\right\|_{L^{\infty}\left(0, T ; L^{2}(\Omega)\right)}^{2}+\left\|p-p\left(u_{h}\right)\right\|_{L^{2}\left(0, T ; H^{1}(\Omega)\right)}^{2} & \leqslant C\left\|y-y\left(u_{h}\right)\right\|_{L^{2}\left(0, T ; L^{2}(\Omega)\right)}^{2} \\
& \leqslant C\left\|u-u_{h}\right\|_{L^{2}\left(0, T ; L^{2}\left(\Omega_{U}\right)\right)^{\prime}}^{2}
\end{aligned}
$$

we can easily obtain (4.11). The proof of Theorem 4.1 is completed.

\section{A Posteriori Error Estimates in Integral}

Often we need sharper a posteriori error estimates. Then we need deriving the a posteriori error estimates in $L^{2}\left(0, T ; L^{2}(\Omega)\right)$-norm. To this end we first state the main results in this paper.

\subsection{Main Results}

We have the following results.

Theorem 5.1. Let $(y, u)$ and $\left(y_{h}, u_{h}\right)$ be the solutions of $(O C P)$ and $(O C P)^{h}$, respectively. Let $p$ and $p_{h}$ be the solution of the costate equations (3.2) and (3.10). Then there hold the a posteriori error estimates

$$
\left\|u-u_{h}\right\|_{L^{2}\left(0, T ; L^{2}\left(\Omega_{U}\right)\right)}^{2}+\left\|y-y_{h}\right\|_{L^{2}\left(0, T ; L^{2}(\Omega)\right)}^{2}+\left\|p-p_{h}\right\|_{L^{2}\left(0, T ; L^{2}(\Omega)\right)}^{2} \leqslant C\left(\eta_{1}^{2}+\sum_{i=2}^{5} \xi_{i}^{2}+\eta_{6}^{2}\right),
$$


where $\eta_{1}^{2}, \eta_{6}^{2}$ is defined in Theorem 4.1 and

$$
\begin{aligned}
& \xi_{2}^{2}=\int_{0}^{T}\left\{\sum_{\tau} h_{\tau}^{4} \int_{\tau}\left(\frac{\partial}{\partial t} p_{h}+\operatorname{div}\left(A^{*} \nabla p_{h}\right)+\int_{t}^{T} \operatorname{div}\left(C^{*}(\tau, t) \nabla p_{h}(\tau)\right) d \tau+y_{h}-z_{d}\right)^{2}\right\} d t \\
& \xi_{3}^{2}=\int_{0}^{T} \sum_{\tau} h_{l}^{3} \int_{\partial \tau}\left[\left(A^{*} \nabla p_{h}\right) \cdot n+\int_{t}^{T}\left(C^{*}(\tau, t) \nabla p_{h}(\tau)\right) \cdot n d \tau\right]^{2} d l d t \\
& \xi_{4}^{2}=\int_{0}^{T}\left\{\sum_{\tau} h_{\tau}^{4} \int_{\tau}\left(\frac{\partial}{\partial t} y_{h}-\operatorname{div}\left(A \nabla y_{h}\right)-\int_{0}^{t} \operatorname{div}\left(C(t, \tau) \nabla y_{h}(\tau)\right) d \tau-f-B u_{h}\right)^{2}\right\} d t \\
& \xi_{5}^{2}=\int_{0}^{T} \sum_{\tau} h_{l}^{3} \int_{\partial \tau}\left[\left(A \nabla y_{h}\right) \cdot n+\int_{0}^{t}\left(C(t, \tau) \nabla y_{h}(\tau)\right) \cdot n d \tau\right]^{2} d l d t .
\end{aligned}
$$

In order to prove Theorem 5.1, we need the following dual equations and lemmas.

\subsection{Dual Equations and Some Lemmas}

For given $F \in L^{2}\left(0, T ; L^{2}(\Omega)\right)$ and the following equation:

$$
\begin{gathered}
\frac{\partial}{\partial t} \phi-\operatorname{div}(A \nabla \phi)-\int_{0}^{t} \operatorname{div}(C(t, \tau) \nabla \phi(\tau)) d \tau=F, \quad(x, t) \in \Omega \times(0, T], \\
\phi \partial \Omega=0, \quad t \in(0, T] \\
\phi(x, 0)=0, \quad x \in \Omega,
\end{gathered}
$$

we have its dual equation:

$$
\begin{gathered}
-\frac{\partial}{\partial t} \psi-\operatorname{div}\left(A^{*} \nabla \psi\right)-\int_{t}^{T} \operatorname{div}\left(C^{*}(\tau, t) \nabla \psi(\tau)\right) d \tau=F, \quad(x, t) \in \Omega \times(0, T], \\
\psi \partial \Omega=0, \quad t \in(0, T], \\
\psi(x, T)=0, \quad x \in \Omega .
\end{gathered}
$$

In order to derive a posteriori error estimates in $L^{2}$-norm, it is necessary to have some stability results of the dual equations. From $[17-19,29]$, we have the following stability results. 
Lemma 5.2. Assume that $\phi$ and $\psi$ are the solution of (5.3) and (5.4), respectively. Then

$$
\begin{aligned}
& \|\phi\|_{L^{\infty}\left(0, T ; L^{2}(\Omega)\right)} \leqslant C\|F\|_{L^{2}\left(0, T ; L^{2}(\Omega)\right)} \\
& \|\nabla \phi\|_{L^{2}\left(0, T ; L^{2}(\Omega)\right)} \leqslant C\|F\|_{L^{2}\left(0, T ; L^{2}(\Omega)\right)} \\
& \left\|D^{2} \phi\right\|_{L^{2}\left(0, T ; L^{2}(\Omega)\right)} \leqslant C\|F\|_{L^{2}\left(0, T ; L^{2}(\Omega)\right)} \\
& \left\|\frac{\partial}{\partial t} \phi\right\|_{L^{2}\left(0, T ; L^{2}(\Omega)\right)} \leqslant C\|F\|_{L^{2}\left(0, T ; L^{2}(\Omega)\right)} \\
& \|\psi\|_{L^{\infty}\left(0, T ; L^{2}(\Omega)\right)} \leqslant C\|F\|_{L^{2}\left(0, T ; L^{2}(\Omega)\right)} \\
& \|\nabla \psi\|_{L^{2}\left(0, T ; L^{2}(\Omega)\right)} \leqslant C\|F\|_{L^{2}\left(0, T ; L^{2}(\Omega)\right)} \\
& \left\|D^{2} \psi\right\|_{L^{2}\left(0, T ; L^{2}(\Omega)\right)} \leqslant C\|F\|_{L^{2}\left(0, T ; L^{2}(\Omega)\right)} \\
& \left\|\frac{\partial}{\partial t} \psi\right\|_{L^{2}\left(0, T ; L^{2}(\Omega)\right)} \leqslant C\|F\|_{L^{2}\left(0, T ; L^{2}(\Omega)\right)}
\end{aligned}
$$

where $D^{2} \phi=\partial^{2} \phi / \partial x_{i} \partial x_{j}, 1 \leqslant i, j \leqslant n$, and $D^{2} \psi$ is defined similarly.

It follows from Lemmas 4.2 and 5.2 that we have the following upper bounds.

Lemma 5.3. Let $(y, u)$ and $\left(y_{h}, u_{h}\right)$ be the solutions of $(O C P)$ and $(O C P)^{h}$, respectively. Let $p$ and $p_{h}$ be the solution of the costate equations (3.2) and (3.10). Then there hold the a posteriori error estimates

$$
\left\|y_{h}-y\left(u_{h}\right)\right\|_{L^{2}\left(0, T ; L^{2}(\Omega)\right)}^{2}+\left\|p_{h}-p\left(u_{h}\right)\right\|_{L^{2}\left(0, T ; L^{2}(\Omega)\right)}^{2} \leqslant C\left(\sum_{i=2}^{5} \xi_{i}^{2}+\eta_{6}^{2}\right)
$$

Proof. It follows from Lemma 4.2 that we only need to estimate $\left\|p_{h}-p\left(u_{h}\right)\right\|_{L^{2}\left(0, T ; L^{2}(\Omega)\right)}^{2}$.

Let $\phi$ be the solution of (5.3) with $F=p_{h}-p\left(u_{h}\right)$ and $\phi_{I}=\widehat{\pi}_{h} \phi$ be the interpolation of $\phi$ in Lemma 3.2.

It follows from (5.3), (4.29) and by integrating by parts

$$
\begin{aligned}
& \left\|p_{h}-p\left(u_{h}\right)\right\|_{L^{2}\left(0, T ; L^{2}(\Omega)\right)}^{2}=\int_{0}^{T}\left(F(t),\left(p_{h}-p\left(u_{h}\right)\right)(t)\right) d t \\
& \quad=\int_{0}^{T}\left[-\left(\frac{\partial}{\partial t}\left(p_{h}-p\left(u_{h}\right)\right), \phi\right)+a\left(\phi, p_{h}-p\left(u_{h}\right)\right)+\int_{0}^{t} c\left(t, \tau ; \phi(\tau),\left(p_{h}-p\left(u_{h}\right)\right)(t)\right) d \tau\right] d t
\end{aligned}
$$




$$
\begin{aligned}
&=\int_{0}^{T}[-\left(\frac{\partial}{\partial t} p_{h}, \phi-\phi_{I}\right)+a\left(\phi-\phi_{I}, p_{h}\right)+\int_{t}^{T} c\left(\tau, t ;\left(\phi-\phi_{I}\right)(t), p_{h}(\tau)\right) d \tau \\
&+\left(\frac{\partial}{\partial t} p\left(u_{h}\right), \phi-\phi_{I}\right)-a\left(\phi-\phi_{I}, p\left(u_{h}\right)\right)-\int_{t}^{T} c\left(\tau, t ;\left(\phi-\phi_{I}\right)(t), p\left(u_{h}\right)(\tau)\right) d \tau \\
&\left.\quad-\left(\frac{\partial}{\partial t}\left(p_{h}-p\left(u_{h}\right)\right), \phi_{I}\right)+a\left(\phi_{I}, p_{h}-p\left(u_{h}\right)\right)+\int_{t}^{T} c\left(\tau, t ; \phi_{I}(t),\left(p_{h}-p\left(u_{h}\right)\right)(\tau)\right) d \tau\right] d t \\
&=\int_{0}^{T}\left\{\sum_{\tau} \int_{\tau}\left(\frac{\partial}{\partial t} p_{h}+\operatorname{div}\left(A^{*} \nabla p_{h}\right)+\int_{t}^{T} \operatorname{div}\left(C^{*}(\tau, t) \nabla p_{h}(\tau)\right) d \tau+y_{h}-z_{d}\right)\left(\phi-\phi_{I}\right)\right\} d t \\
& \quad+\int_{0}^{T} \sum_{\tau} \int_{\partial \tau}\left[\left(A^{*} \nabla p_{h}\right) \cdot n+\int_{t}^{T}\left(C^{*}(\tau, t) \nabla p_{h}(\tau)\right) \cdot n d \tau\right]\left(\phi-\phi_{I}\right) d l d t+\int_{0}^{T}\left(y_{h}-y\left(u_{h}\right), \phi\right) d t \\
&=J_{1}+J_{2}+J_{3} .
\end{aligned}
$$

By Lemmas 3.2, 3.4, and 5.2, we obtain

$$
\begin{aligned}
& J_{1} \leqslant C(\delta) \int_{0}^{T}\left\{\sum_{\tau} h_{\tau}^{4} \int_{\tau}\left(\frac{\partial}{\partial t} p_{h}+\operatorname{div}\left(A^{*} \nabla p_{h}\right)+\int_{t}^{T} \operatorname{div}\left(C^{*}(\tau, t) \nabla p_{h}(\tau)\right) d \tau+y_{h}-z_{d}\right)^{2}\right\} d t \\
&+\delta \int_{0}^{T}|\phi|_{2, \Omega}^{2} d t \leqslant C(\delta) \xi_{2}^{2}+\delta\left\|p_{h}-p\left(u_{h}\right)\right\|_{L^{2}\left(0, T ; L^{2}(\Omega)\right)^{\prime}}^{2} \\
& J_{2} \leqslant C(\delta) \int_{0}^{T} \sum_{\tau} h_{l}^{3} \int_{\partial \tau}\left[\left(A^{*} \nabla p_{h}\right) \cdot n+\int_{t}^{T}\left(C^{*}(\tau, t) \nabla p_{h}(\tau)\right) \cdot n d \tau\right]^{2} d l d t+\delta \int_{0}^{T}|\phi|_{0, \Omega}^{2} d t \\
& \leqslant C(\delta) \xi_{3}^{2}+\delta\left\|p_{h}-p\left(u_{h}\right)\right\|_{L^{2}\left(0, T ; L^{2}(\Omega)\right)}^{2} .
\end{aligned}
$$

By Schwartz inequality

$$
J_{3} \leqslant C(\delta)\left\|y_{h}-y\left(u_{h}\right)\right\|_{L^{2}\left(0, T ; L^{2}(\Omega)\right)}^{2}+\delta\left\|p_{h}-p\left(u_{h}\right)\right\|_{L^{2}\left(0, T ; L^{2}(\Omega)\right)}^{2} .
$$

Letting $\delta$ be small enough, it follows from (5.7)-(5.9)

$$
\left\|p_{h}-p\left(u_{h}\right)\right\|_{L^{2}\left(0, T ; L^{2}(\Omega)\right)}^{2} \leqslant C \sum_{i=2}^{3} \xi_{i}^{2}+C\left\|y_{h}-y\left(u_{h}\right)\right\|_{L^{2}\left(0, T ; L^{2}(\Omega)\right)}^{2} .
$$

Similarly, let $\psi$ be the solution of (5.4) with $F=y_{h}-y\left(u_{h}\right)$ and $\psi_{I}=\widehat{\pi}_{h} \phi$ be the interpolation of $\phi$ in Lemma 3.2. 
From (4.38) and by integrating by parts, we have that

$$
\begin{aligned}
\| y_{h}- & \left.y\left(u_{h}\right) \|_{L^{2}\left(0, T ; L^{2}(\Omega)\right.}^{2}\right) \\
= & \int_{0}^{T}\left(F(t),\left(y_{h}-y\left(u_{h}\right)\right)(t)\right) d t \\
= & \int_{0}^{T}\left[\left(\frac{\partial}{\partial t}\left(y_{h}-y\left(u_{h}\right)\right), \psi\right)+a\left(y_{h}-y\left(u_{h}\right), \psi\right)+\int_{t}^{T} c\left(\tau, t ;\left(y_{h}-y\left(u_{h}\right)\right)(t), \psi(\tau)\right) d \tau\right] d t \\
& +\left(y_{0}^{h}-y_{0}, \psi(0)\right)=\int_{0}^{T}\left[\left(\frac{\partial}{\partial t} y_{h}, \psi-\psi_{I}\right)+a\left(y_{h}, \psi-\psi_{I}\right)+\int_{0}^{t} c\left(t, \tau ; y_{h}(\tau),\left(\psi-\psi_{I}\right)(t)\right) d \tau\right] d t \\
& -\int_{0}^{T}\left[\left(\frac{\partial}{\partial t} y\left(u_{h}\right), \psi-\psi_{I}\right)+a\left(y\left(u_{h}\right), \psi-\psi_{I}\right)\right. \\
& \left.\quad+\int_{0}^{t} c\left(t, \tau ; y\left(u_{h}\right)(\tau),\left(\psi-\psi_{I}\right)(t)\right) d \tau\right] d t+\left(y_{0}^{h}-y_{0}, \psi(0)\right) \\
= & \int_{0}^{T}\left\{\sum_{\tau} \int_{\tau}\left(\frac{\partial}{\partial t} y_{h}-\operatorname{div}\left(A \nabla y_{h}\right)-\int_{0}^{t} \operatorname{div}\left(C(\tau, t) \nabla y_{h}(\tau)\right) d \tau-f-B u_{h}\right)\left(\psi-\psi_{I}\right)\right\} d t \\
& +\int_{0}^{T} \sum_{\tau} \int_{\partial \tau}\left[\left(A \nabla y_{h}\right) \cdot n-\int_{0}^{t}\left(C(t, \tau) \nabla y_{h}(\tau)\right) \cdot n\right] d \tau\left(\psi-\psi_{I}\right) d l d t \\
& +\left(y_{0}^{h}-y_{0}, \psi(0)\right)=D_{1}+D_{2}+D_{3} .
\end{aligned}
$$

Similarly, it follows from Lemmas 3.2, 3.4, and 5.2 that

$$
\begin{aligned}
& D_{1} \leqslant C(\delta) \int_{0}^{T}\left\{\sum_{\tau} h_{\tau}^{4} \int_{\tau}\left(\frac{\partial}{\partial t} y_{h}-\operatorname{div}\left(A \nabla y_{h}\right)-\int_{0}^{t} \operatorname{div}\left(C(\tau, t) \nabla y_{h}(\tau)\right) d \tau-f-B u_{h}\right)^{2}\right\} d t \\
& \quad+\delta \int_{0}^{T}|\psi|_{2, \Omega}^{2} d t \leqslant C \xi_{4}^{2}+\delta\left\|y_{h}-y\left(u_{h}\right)\right\|_{L^{2}\left(0, T ; L^{2}(\Omega)\right)^{\prime}}^{2} \\
& D_{2} \leqslant C(\delta) \int_{0}^{T} \sum_{\tau} h_{l}^{3} \int_{\partial \tau}\left[\left(A \nabla y_{h}\right) \cdot n-\int_{0}^{t}\left(C(t, \tau) \nabla y_{h}(\tau)\right) \cdot n\right]^{2} d l d t+\delta \int_{0}^{T}|\psi|_{2, \Omega}^{2} d t \\
& \leqslant C \xi_{5}^{2}+\delta\left\|y_{h}-y\left(u_{h}\right)\right\|_{L^{2}\left(0, T ; L^{2}(\Omega)\right)^{\prime}}^{2} \\
& D_{3} \leqslant C \eta_{6}^{2}+\delta\left\|y_{h}-y\left(u_{h}\right)\right\|_{L^{2}\left(0, T ; L^{2}(\Omega)\right)^{\prime}}^{2} .
\end{aligned}
$$


Letting $\delta$ be small enough, then from (5.11)-(5.12) we have

$$
\left\|y_{h}-y\left(u_{h}\right)\right\|_{L^{2}\left(0, T ; L^{2}(\Omega)\right)}^{2} \leqslant C\left(\xi_{4}^{2}+\xi_{5}^{2}+\eta_{6}^{2}\right)
$$

Then (5.6) follows from (5.10)-(5.13). The proof of Lemma 5.3 is completed.

\subsection{Proof of Theorem 5.1}

From Lemmas 4.2 and 5.3, we can easily prove Theorem 5.1 .

Proof. By triangle inequality, (4.45), Lemmas 4.2 and 5.3, we can easily prove (5.1) in the same way of getting (4.11). The proof of Theorem 5.1 is completed.

\section{Conclusion}

In this paper, we first briefly introduce optimal control problem governed by parabolic integrodifferential equations and give the weak formulation for this optimal control problem. For this formulation, we prove the existence and uniqueness of the solution. Then by the theory of optimal control problem, we present the optimality conditions and semidiscrete finite element approximation scheme. The upper a posteriori error estimates for firstorder derivative and $L^{2}\left(0, T ; L^{2}(\Omega)\right)$-norm are derived for both the state and the control approximation for the case of an integral obstacle constraint. We will research on the upper and lower a posteriori error estimates for full discrete finite element approximations of this control problem.

\section{Acknowledgments}

This research was supported by Science and Technology Development Planning Project of Shandong Province (no. 2011GGH20118) and Shandong Province Natural Science Foundation (nos. ZR2012AQ024 and ZR2012GM018).

\section{References}

[1] W. Alt, "On the approximation of infinite optimization problems with an application to optimal control problems," Applied Mathematics and Optimization, vol. 12, no. 1, pp. 15-27, 1984.

[2] R. S. Falk, "Approximation of a class of optimal control problems with order of convergence estimates," Journal of Mathematical Analysis and Applications, vol. 44, pp. 28-47, 1973.

[3] D. A. French and J. T. King, "Approximation of an elliptic control problem by the finite element method," Numerical Functional Analysis and Optimization, vol. 12, no. 3-4, pp. 299-314, 1991.

[4] K. Malanowski, "Convergence of approximations vs. regularity of solutions for convex, controlconstrained optimal-control problems," Applied Mathematics and Optimization, vol. 8, no. 1, pp. 69-95, 1982.

[5] P. Neittaanmäki and D. Tiba, Optimal Control of Nonlinear Parabolic Systems, Theory, Algorithms, and Applications, vol. 179 of Monographs and Textbooks in Pure and Applied Mathematics, Marcel Dekker, New York, NY, USA, 1994.

[6] O. Pironneau, Optimal Shape Design for Elliptic Systems, Springer Series in Computational Physics, Springer, New York, NY, USA, 1984. 
[7] D. Tiba, Lectures on the Optimal Control of Elliptic Equations, University of Jyvaskyla Press, Finland, 1995.

[8] D. Tiba, Optimal control of nonsmooth distributed parameter systems, vol. 1459 of Lecture Notes in Mathematics, Springer, Berlin, Germany, 1990.

[9] D. Tiba and F. Tröltzsch, "Error estimates for the discretization of state constrained convex control problems," Numerical Functional Analysis and Optimization, vol. 17, no. 9-10, pp. 1005-1028, 1996.

[10] T. J. Sun, "Equivalent a posteriori error estimates for a constrained optimal control problem governed by parabolic equations," International Journal of Numerical Analysis and Modeling. In press.

[11] W. Liu and N. Yan, "A posteriori error estimates for optimal control problems governed by parabolic equations," Numerische Mathematik, vol. 93, no. 3, pp. 497-521, 2003.

[12] P. G. Ciarlet, The Finite Element Method for Elliptic Problems, North-Holland Publishing, Amsterdam, The Netherlands, 1978.

[13] J. Haslinger and P. Neittanmaki, Finite Element Approximation for Optimal Shape Design, John Wiley \& Sons, Chichester, UK, 1989.

[14] A. Friedman and M. Shinbrot, "Volterra integral equations in Banach space," Transactions of the American Mathematical Society, vol. 126, pp. 131-179, 1967.

[15] M. L. Heard, "An abstract parabolic Volterra integro-differential equation," SIAM Journal on Mathematical Analysis, vol. 13, no. 1, pp. 81-105, 1982.

[16] M. Renardy, W. J. Hrusa, and J. A. Nohel, Mathematical Problems in Viscoelasticity, vol. 35 of Pitman Monographs and Surveys in Pure and Applied Mathematics, Longman Scientific \& Technical, Harlow, UK, 1987.

[17] J. R. Cannon, Y. Lin, and C. Y. Xie, “Galerkin methods and $L^{2}$-error estimates for hyperbolic integrodifferential equations," Calcolo, vol. 26, no. 2-4, pp. 197-207, 1989.

[18] I. H. Sloan and V. Thomée, "Time discretization of an integro-differential equation of parabolic type," SIAM Journal on Numerical Analysis, vol. 23, no. 5, pp. 1052-1061, 1986.

[19] E. G. Yanik and G. Fairweather, "Finite element methods for parabolic and hyperbolic partial integrodifferential equations," Nonlinear Analysis. Theory, Methods E Applications, vol. 12, no. 8, pp. 785-809, 1988.

[20] W. Liu and N. Yan, "A posteriori error estimates for distributed convex optimal control problems," Advances in Computational Mathematics, vol. 15, no. 1-4, pp. 285-309, 2001.

[21] W. Liu and N. Yan, "A posteriori error estimates for convex boundary control problems," SIAM Journal on Numerical Analysis, vol. 39, no. 1, pp. 73-99, 2001.

[22] H. Brunner and N. Yan, "Finite element methods for optimal control problems governed by integral equations and integro-differential equations," Numerische Mathematik, vol. 101, no. 1, pp. 1-27, 2005.

[23] J. L. Lions and E. Magenes, Non Homogeneous Boundary Value Problems and Applications, vol. 181 of Grundlehren der Mathematischen Wissenschaften, Springer, 1972.

[24] J.-L. Lions, Optimal Control of Systems Governed by Partial Differential Equations, Springer, New York, NY, USA, 1971.

[25] L. R. Scott and S. Zhang, "Finite element interpolation of nonsmooth functions satisfying boundary conditions," Mathematics of Computation, vol. 54, no. 190, pp. 483-493, 1990.

[26] A. Kufner, O. John, and S. Fučík, Function Spaces, Noordhoff International Publishing, Leyden, The Netherlands, 1977.

[27] Y. Q. Huang, R. Li, W. B. . Liu, and N. N. Yan, “Adaptive multi-mesh finite element approximation for con- strained optimal control," SIAM Journal on Control and Optimization. In press.

[28] W. Shen and H. Su, "Adaptive finite element method for optimal control problem governed by linear quasi-parabolic integro-differential equations," Abstract and Applied Analysis, vol. 2012, Article ID 808514, 26 pages, 2012.

[29] V. Thomée and N.-Y. Zhang, "Error estimates for semidiscrete finite element methods for parabolic integro-differential equations," Mathematics of Computation, vol. 53, no. 187, pp. 121-139, 1989. 


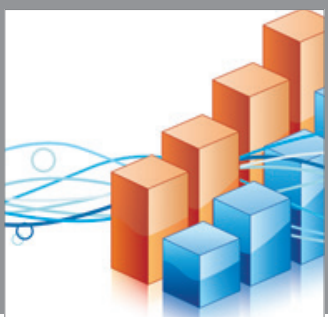

Advances in

Operations Research

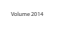

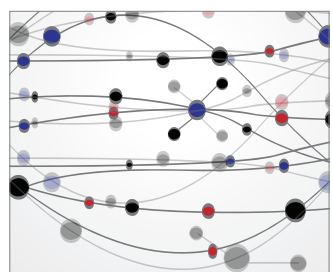

\section{The Scientific} World Journal
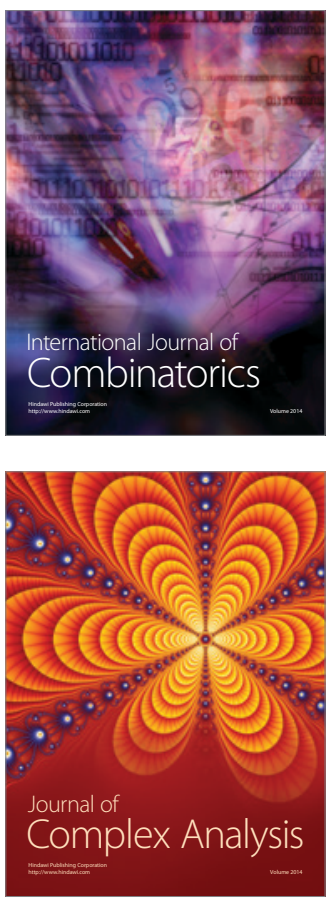

International Journal of

Mathematics and

Mathematical

Sciences
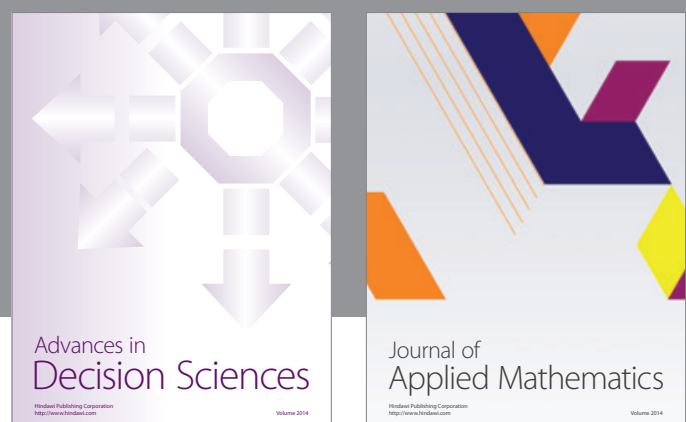

Journal of

Applied Mathematics
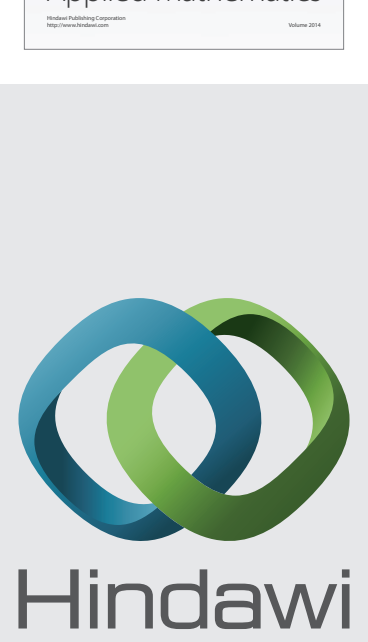

Submit your manuscripts at http://www.hindawi.com
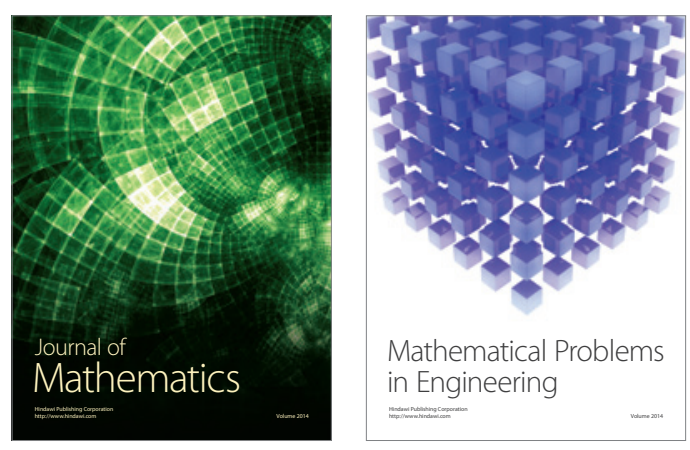

Mathematical Problems in Engineering
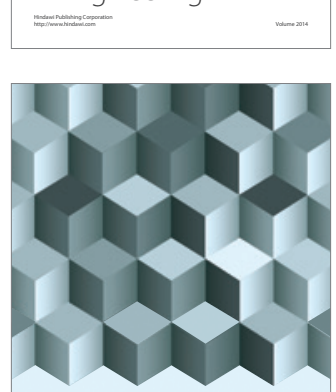

Journal of

Function Spaces
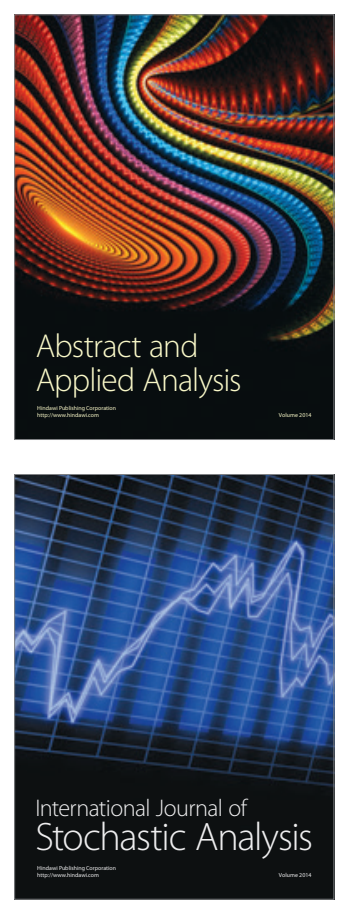

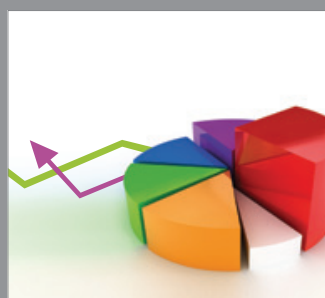

ournal of

Probability and Statistics

Promensencen
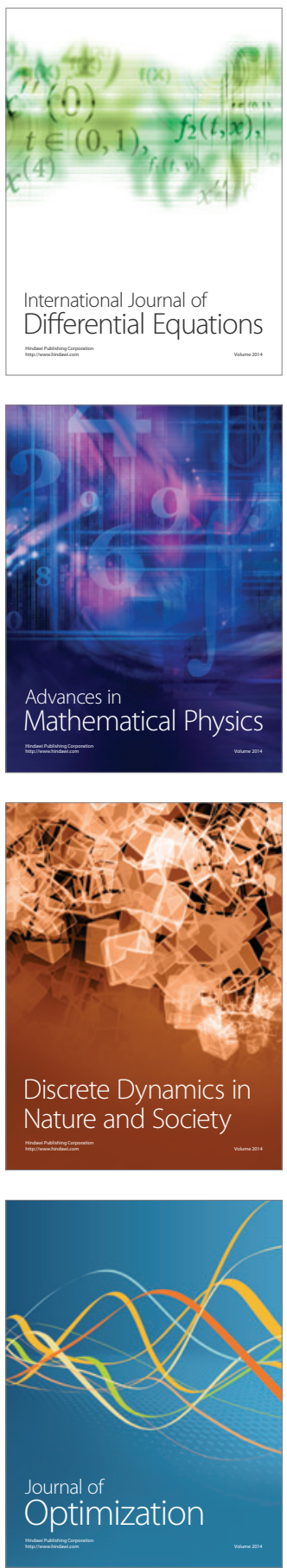